\title{
AIRSA
}

AKSA JURNAL DESAIN KOMUNIKASI VISUAL

ISSN: 2615-1111 (online)

Available online at:

JURNAL DESAIN KOMUNIKASI VISUAL

http://jurnalaksa.stsrdvisi.ac.id

\section{PERANCANGAN PROTOTYPE WEB PROFILE DESA WISATA DAN KERAJINAN GAMPLONG SLEMAN DENGAN METODE DESAIN USER EXPERIENCE}

\author{
Dian Prajarini \\ Sekolah Tinggi Seni Rupa dan Desain Visi Indonesia \\ E-mail: dianpraja@gmail.com ${ }^{1}$
}

\begin{tabular}{|c|c|}
\hline ARTICLE INFO & ABSTRAK \\
\hline $\begin{array}{l}\text { Article history: } \\
\text { Received: } 1 \text { Oktober } 2018 \\
\text { Revised: } 10 \text { Oktober } 2018 \\
\text { Accepted: } 13 \text { Oktober } 2018\end{array}$ & $\begin{array}{l}\text { Gamplong Tourism Village and Craft at Sleman Regency are one of } \\
\text { the alternative tourist destinations of Yogyakarta Special Region. } \\
\text { This tourist village presents weaving craft tours. There are } \\
\text { approximately } 18 \text { weaving craftsmen in this tourist village. The }\end{array}$ \\
\hline $\begin{array}{l}\text { Keywords: } \\
\text { User Experience } \\
\text { Web profile } \\
\text { Heuristic }\end{array}$ & $\begin{array}{l}\text { promotions that have been carried out so far are still using leaflet } \\
\text { and social media usage methods. It is an obstacle when social media } \\
\text { does not provide clear information for tour packages in Gamplong } \\
\text { tourism and craft villages. The absence of a website as a showroom } \\
\text { and provider of information about the details of Gamplong tourism } \\
\text { villages and handicrafts. } \\
\text { This research develops a Gamplong village tourism and craft web } \\
\text { profile prototype uses user experience design method. The design } \\
\text { method uses five planes user experience elements. The design result } \\
\text { evaluation method uses a heuristic evaluation method. } \\
\text { The results of the study succeeded in creating a prototype web } \\
\text { profile of Gamplong Tourism Village and Craft with user experience } \\
\text { design method. The heuristic evaluation results on the interface of } \\
\text { the Gamplong Tourism Village's prototype web profile and } \\
\text { Handicraft as a reference for usability evaluation, suggesting that } \\
\text { aesthetics, design, and match with the real, but need better handling } \\
\text { for error prevention, adding help menus, and bilingual features. }\end{array}$ \\
\hline
\end{tabular}

\section{PENDAHULUAN}

Desa Wisata dan Kerajinan Gamplong merupakan salah satu desa wisata yang ada di Kabupaten Sleman tepatnya di Dusun Gamplong, Desa Sumberahayu, Kecamatan Moyudan. Dusun Gamplong sendiri merupakan sebuah dusun yang menjadi sentra kerajinan tenun di Kab. Sleman. Terdapat 18 pengrajin tenun yang tergabung dalam paguyuban 'TEGAR'. Kerajinan yang dihasilkan oleh pengrajin paguyuban 'TEGAR' utamanya adalah kerajinan tenun dengan bahan mulai dari benang, enceng gondok, mendong, ranting, lidi. Hasil tenun dibentuk menjadi berbagai macam bentuk sebagai contoh, tas, tempat tisu, tempat pensil, karpet, alas makan, 
taplak meja. Selain produk kerajinan tenun, ada pula produk kerajinan non tenun seperti rajut, kulit dan penggunaan pasir untuk produk pigura, celengan, kotak pensil.

Keunikan Dusun Gamplong dan kegigihan mereka melestarikan ketrampilan warisan turun temurun dari orang tua mereka membuat Dusun Gamplong diresmikan menjadi Desa Wisata dan Kerajinan pada akhir tahun 2015. Gamplong menyuguhkan destinasi wisata berupa pengenalan kerajinan tenun dan non tenun, pelatihan tenun, tour ke rumah pengrajin dan melibatkan peserta atau wisatawan membuat kerajinan yang sederhana.

Hasil kerajinan tenun Gamplong sudah dikirim ke beberapa pulau di Indonesia bahkan sudah diekspor ke luar negeri selain dikirim ke pedagang di tempat wisata atau di ke pedagang di kawasan malioboro. Konsumen kerajinan tenun Gamplong memperoleh informasi melalui media mulut ke mulut melalui orang-orang yang sudah menjadi pelanggan. Promosi paket wisata dilakukan dengan pembuatan lefleat yang akan diberikan atau bisa diambil pengunjung saat datang ke Dusun Gamplong serta dibagikan saat pengrajin mengikuti pameran-pameran. Penggunaan media sosial juga sudah digunakan oleh masing-masing pengrajin untuk melakukan promosi produk, bahkan sudah ada akun media sosial khusus untuk Desa Wisata Gamplong walaupun isinya masih dicampur dengan kegiatan pribadi. Media sosial khusus untuk desa wisata Gamplong juga tidak memperlihatkan informasi wisata dan kerajinan tenun yang dihasilkan.

Berdasarkan penjabaran sebelumnya, penyebarluasan informasi desa wisata dan kerajinan Gamplong meskipun sudah memanfaatkan Internet ternyata masih kurang. Promosi atau penyampaian informasi yang kurang menyebabkan kurang berkembangnya daerah wisata (Supriyanta, dkk, 2015). Website sebagai sarana ruang pamer dan penyedia informasi tentang detail sebuah destinasi wisata dibutuhkan untuk meningkatkan kredibilitas destinasi wisata tersebut.

Asdarianto (2017) dalam penelitiannya menggunakan metode five planes user experience element untuk merancang user experience pebisnis pada sistem pemasaran waralaba produk UMKM. Hasil dari penelitian Asdarianto (2017) adalah prototype sistem. Orlova (2016) melakukan pembangunan ulang sebuah web portofolio menggunakan prinsip utama user experience. Dalam penelitiannya, Orlova (2016) juga menggunakan evaluasi heuristik untuk memahami persoalan usability pada website yang sedang berjalan, sebagai masukan dalam membuat desain user experience dengan kesimpulan 3 prinsip usability yaitu 1) kesesuaian antara sistem/aplikasi/web dengan dunia nyata, 2) penggunaan yang fleksibel dan efisien, 3) desainnya memiliki estetika dan minimalis. 
Yeskasafitri, dkk (2015) melakukan perancangan model user interface website $e$ commerce Liliput Edu Toys dalam bentuk paper prototyping dengan tahapan perancangannya yang mengadopsi user experience design process. Keinanen (2011) dalam penelitiannya menghasilkan pedoman user experience pada sebuah website. Ichsan, dkk (2015) membuat pemodelan user experience aplikasi interaktif pengenalan menggambar untuk peserta pendidikan anak usia dini dengan menggunakan metode herarchical task anslysis, sedangkan untuk evaluasinya menggunakan metode evaluasi heuristik.

Moule (2012) mengatakan bahwa user experience (UX) adalah kesatuan rangkaian interaksi pengguna dengan sebuah produk, layanan atau organisasi. User Experience (UX) juga bisa didefinisikan oleh ISO 9241-110:2010 sebagai sebuah persepsi dan tanggapan pengguna setelah menggunakan sebuah sistem, produk atau layanan. Beberapa hal yang mempengaruhi pengalaman pengguna mulai dari kegunaan produk, kemudahan penggunaan (navigasi, interaksi, bantuan) produk, kemudahan mempelajari produk, desain produk dan perasaan saat merespon produk sampai keinginan untuk menggunakan produk. Metode five planes user experience element menurut Garrett (2011) terdiri dari 5 (lima) urutan langkah yaitu strategy plane, scope plane, structure plane, skeleton plane, serta surface plane. Strategy plane merupakan elemen paling bawah atau paling awal dari tahapan yang berisi analisis tujuan bisnis dan kebutuhan pengguna serta perancangan user persona. Scope plane merupakan tahapan untuk menentukan jenis aplikasi yang akan dibuat beserta perangkat yang akan digunakan serta pembuatan skenario pengguna berdasarkan user persona yang telah dihasilkan sebelumnya. Structure plane berisi artitektur informasi dan desain interaksi. Skeleton plane berisi rancangan prototype berdasarkan desain interaksi yang masih bersifat low fidelity. Sedangkan pada surface plane juga berisi rancangan prototype tetapi sudah bersifat medium fidelity.

Berdasar dari penjabaran masalah dan penelitian-penelitian yang telah dilakukan sebelumnya. Website sebagai sarana menyajikan informasi paket wisata, ruang pamer produk kerajinan tenun dan non tenun, kegiatan wisata yang dilaksanakan dibutuhkan untuk desa wisata dan kerajinan Gamplong dengan memperhatikan aspek user experience (UX) yang memberi kemudahan dan efesiensi bagi pengguna saat berinteraksi dengan website. Dalam proses desain user experience akan menggabungkan metode five planes user experience element dengan memperhatikan pedoman user experience pada sebuah web (Keinanen, 2011). Sedangkan untuk evaluasinya hasil desain antarmuka akan menggunakan metode evaluasi heuristik. 


\section{METODE PERANCANGAN}

\subsection{Data}

Data yang digunakan dalam penelitian ini adalah data yang diperoleh berdasarkan hasil wawancara. Wawancara dilakukan kepada pengurus Paguyuban 'TEGAR' sebagai pengelola Desa Wisata dan Kerajinan Gamplong dan pengrajin kerajinan tenun yang menjadi anggota Paguyuban 'TEGAR'.

\subsection{Perancangan Desain User Experience}

Perancangan prototype user experience web profile dilakukan dalam 5 (lima) tahap, antara lain:

1. Strategy plane, menganalisis tujuan bisnis dan kebutuhan pengguna serta perancangan user persona.

2. Scope plane, menentukan jenis aplikasi yang akan dibuat beserta perangkat yang akan digunakan serta pembuatan skenario pengguna berdasarkan user persona yang telah dihasilkan sebelumnya.

3. Structure plane, menentukan artitektur informasi dan desain interaksi.

4. Skeleton plane, membuat rancangan prototype berdasarkan desain interaksi yang masih bersifat low fidelity.

5. Surface plane, membuat rancangan prototype tetapi sudah bersifat medium fidelity

\subsection{Evaluasi}

Tahap evaluasi digunakan untuk mengevaluasi hasil rancangan prototype untuk melihat apakah ada masalah dalam perancangannya. Evaluasi ini dilakukan dengan metode evaluasi heuristik dengan memeriksa user interface berdasarkan kaidah-kaidah yang telah ditetapkan.

\section{PEMBAHASAN}

\subsection{Deskripsi Data}

\section{Strategi Plane}

Tahapan strategy plane ini digunakan untuk menganalisis tujuan bisnis dan kebutuhan pengguna serta perancangan user persona.

a. Data Wawancara

Wawancara dilakukan untuk mendapatkan data-data terkait umkm, penggunaan perangkat TIK, dan respon atas desain website yang akan dibuat. Wawancara ini 
melibatkan 6 pelaku usaha kerajinan yang tergabung di dalam paguyuban TEGAR Desa Gamplong, Sumberahayu, Moyudan, Sleman, DIY. Enam narasumber tersebut antara lain Giyono, Riski, Waludin, Dwi Kusnardi, Yani dan Marwanto.

Giyono merupakan pemilik usaha kerajinan Gion Craft yang memproduksi tas dengan bahan dari tenun mendong, lidi yang dikombinasikan dengan kulit. Responden berusia 43 tahun sekaligus menjabat sebagai ketua Paguyuban TEGAR. Responden menggunakan perangkat TIK yaitu whatsapp untuk berkomunikasi dengan anggota paguyuban serta menjawab pesanan hasil kerajinan. Selain itu dengan bantuan anaknya menggunakan media sosial Instagram untuk mempromosikan hasil produk kerajinan dan kegiatankegiatan kunjungan di Paguyuban TEGAR. Menginginkan website yang bisa menambah wisatawan yang datang dan berbelanja kerajinan di Gamplong. Riski berusia 19 tahun merupakan putra dari Giyono. Kesehariannya membantu orang tua memproduksi tas kerajinan. Riski membantu orang tua dalam hal penggunaan media sosial khususnya Instagram untuk mempromosikan produk dengan mengunggah foto produk maupun video produk yang dibuatnya. Riski menggunakan e-mail untuk membantu orang tuanya berkomunikasi dengan pihak dinas pemerintahan terkait jika ada acara atau pameran yang melibatkan Desa Wisata Kerajinan Gamplong serta browsing internet.

Waludin merupakan narasumber yang memiliki usaha tenun kerajinan, berusia 46 tahun. Hasil usahanya adalah tenun lidi, tenun mendong, stagen, plismat, rug, tas, asesoris dengan bahan tenun. Menggunakan internet dalam bentuk sosial media facebook dan instagram untuk mempromosikan hasil kerajinan dan kegiatan-kegiatan paguyuban tenun TEGAR. Dwi Kusnardi dan Yani merupakan narasumber yang juga anggota Paguyuban Tegar dengan usaha rajut berupa tas, dompet, sepatu dengan bahan dasar rajut. Dwi Kusnardi menggunakan Instagram dan Facebook untuk mempromosikan hasil kerajinannya. Marwanto berusia 48 tahun merupakan pemilik Amalya Craft, anggota Paguyuban TEGAR memiliki usaha tenun lidi, tenun mendong yang dibuat menjadi taplak meja, plismat. Menggunakan Instagram untuk promosi usahanya. Pada tahun 2016 memiliki akun di website jogjaplaza.com untuk menjual hasil usahanya.

b. Analisis Tujuan Bisnis

Desa Wisata Kerajinan Gamplong membutuhkan website yang digunakan untuk mempromosikan aset wisata kerajinan, paket wisata kerajinan, pelatihan tenun dan pembuatan kerajinan serta mempromosikan produk hasil kerajinan anggota Paguyuban TEGAR dalam bentuk katalog online. Dibutuhkan fitur untuk masing-masing anggota 
Paguyuban TEGAR bisa mengunggah data hasil kerajinan mereka ke dalam katalog online.

c. Kebutuhan Pengguna

Berdasarkan wawancara dengan narasumber, dibutuhkan sebuah website yang mudah, sederhana, tidak ada pop up. Memberikan informasi paket-paket wisata, mengatur datadata wisata kerajinan, menambah data galeri produk untuk masing-masing pengrajin sebagai katalog online.

d. User Persona

User persona yang dihasilkan merupakan penggabungan hasil wawancara dari 6 narasumber dengan menciptakan karakter fiksi mengacu hasil analisis. Ade merupakan responden yang terbiasa menggunakan internet, komputer dan website. Ade merupakan anggota Paguyuban TEGAR serta memiliki usaha kerajinan. Terbiasa dengan komputer dengan sistem operasi windows dan smartphone android dalam mempromosikan hasil usaha dan kegiatan-kegiatan Desa Wisata Kerajinan Gamplong. Membutuhkan website yang sederhana, mudah digunakan, tidak membingungkan untuk mempromosikan kegiatan-kegiatan Desa Wisata Kerajinan Gamplong beserta hasil-hasil kerajinannya.

2. Scope Plane

Tahapan scope plane ini digunakan untuk menentukan jenis aplikasi yang akan dibuat beserta perangkat yang akan digunakan dalam pembuatan aplikasi serta pembuatan skenario pengguna berdasarkan user persona yang telah dihasilkan sebelumnya. Perangkat keras yang digunakan adalah laptop Asus ROG dengan layar 16 inci, prosesor i7. Kartu grafis NVIDIA GeForse GTX 950M, RAM 4 GB. Browser yang digunakan adalah Mozila Firefox. Skenario pengguna, Ade merupakan anggota Paguyuban TEGAR Desa Wisata Kerajinan Gamplong, yang juga memiliki usaha kerajinan hasil tenun. Sebagai admin website yang ditunjuk oleh paguyuban, Ade bisa masuk dan menambah data paket wisata Desa Wisata Kerajinan Gamplong. Ade juga bisa mengunggah foto-foto kegiatan-kegiatan wisata, dan fasilitas yang disediakan Desa Wisata Kerajinan Gamplong. Selain itu, Ade juga bisa mengunggah foto hasil kerajinan paguyuban TEGAR dalam galeri produk sebagai katalog online dengan mudah, sederhana, dan tidak mengalami kebingungan.

\section{Structure Plane}

Tahap structure plane ini digunakan untuk menentukan artitektur informasi dan desain interaksi. Arsitektur informasi ini dapat terlihat pada peta situs berikut. 


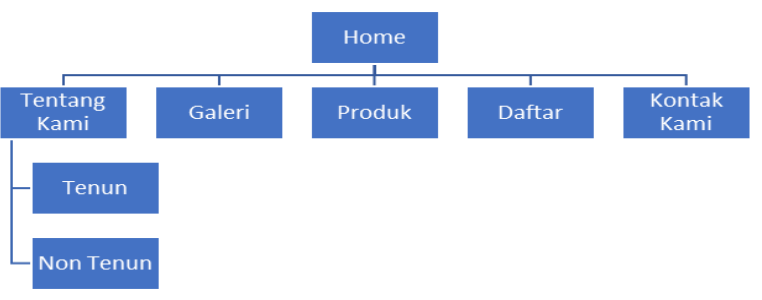

Gambar 1. Peta Situs

(Sumber: Dokumentasi Penulis)

\section{Skeleton Plane}

Tahap skeleton plane ini digunakan untuk membuat rancangan prototype berdasarkan desain interaksi yang masih bersifat low fidelity. Perancangan ini digunakan untuk merancang antarmuka website Desa Wisata Kerajinan Gamplong sebagai gambaran dalam pengembangan antarmuka. Rancangan ini masih berupa rancangan kasar menggunakan layout wireframe.

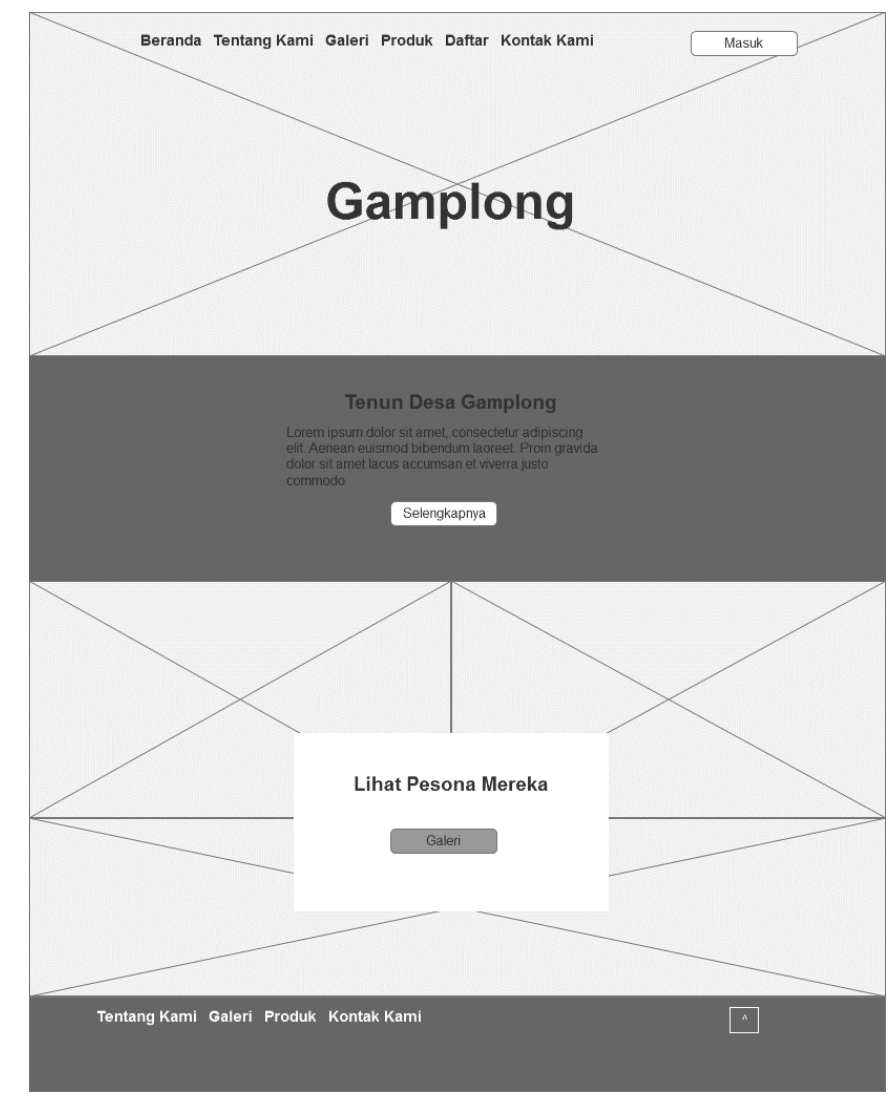

Gambar 2. Wireframe halaman beranda

(Sumber: Dokumentasi Penulis) 


\section{Surface Plane}

Tahap surface plane ini digunakan untuk membuat rancangan prototype berdasarkan desain interaksi yang masih bersifat medium fidelity. Menerapkan elemen visual berupa warna, ikon, tipografi. Tipografi yang digunakan adalah Font Awesome, Nurito Sans dan Open Sans. Warna utama yang digunakan adalah coklat, putih dan abu-abu.

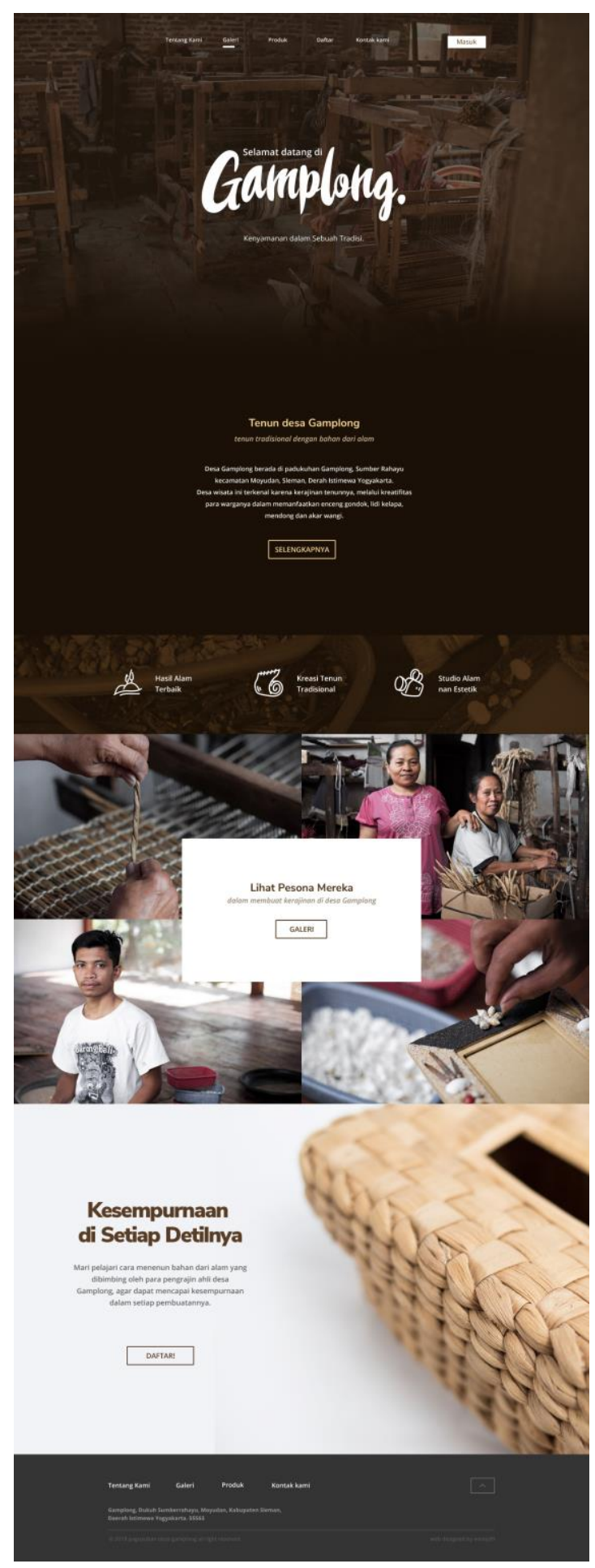

Gambar 3. Halaman beranda (Sumber: Dokumentasi Penulis)
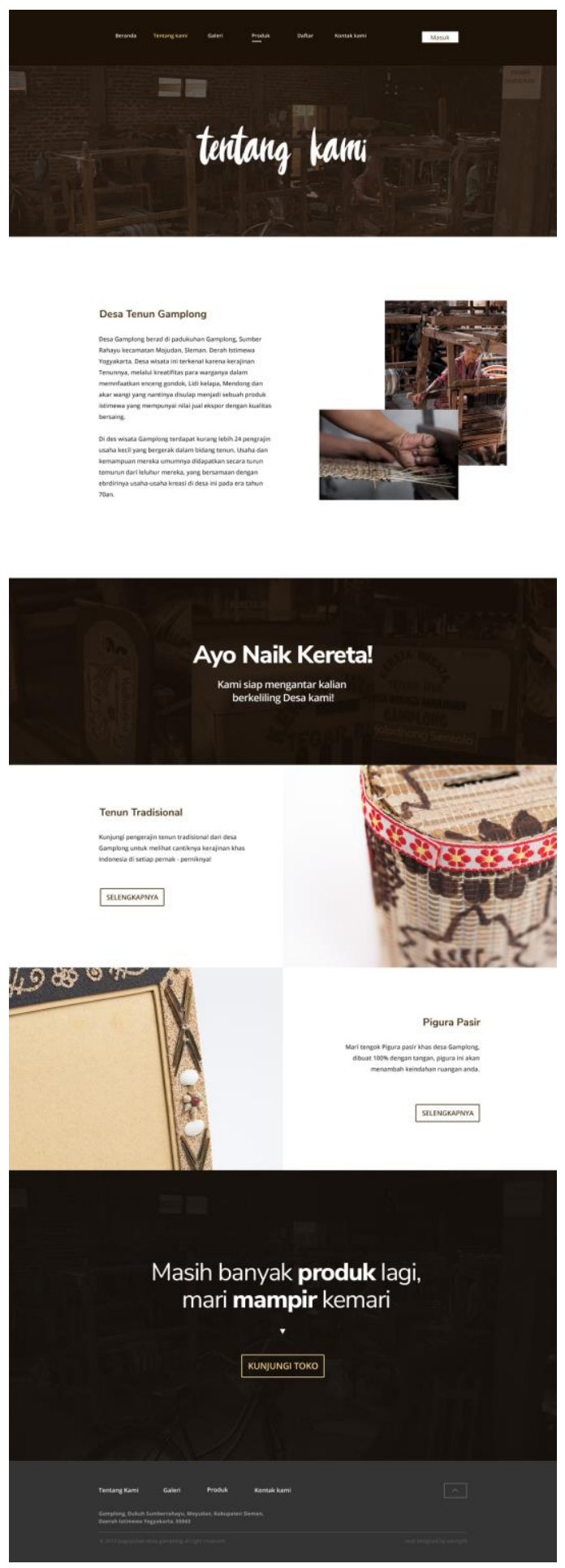

Gambar 4. Halaman tentang kami (Sumber: Dokumentasi Penulis) 


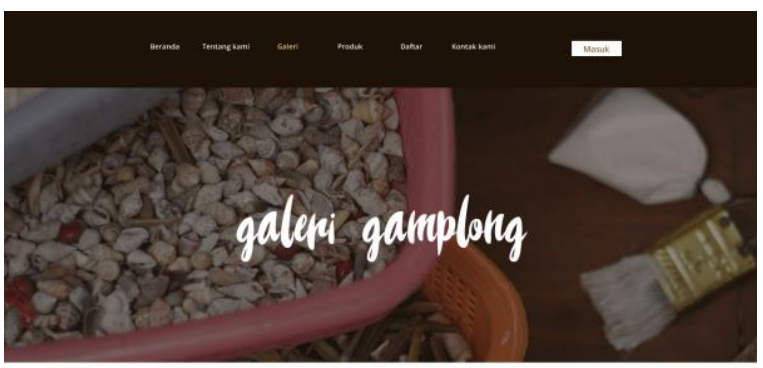

tenet pamaram

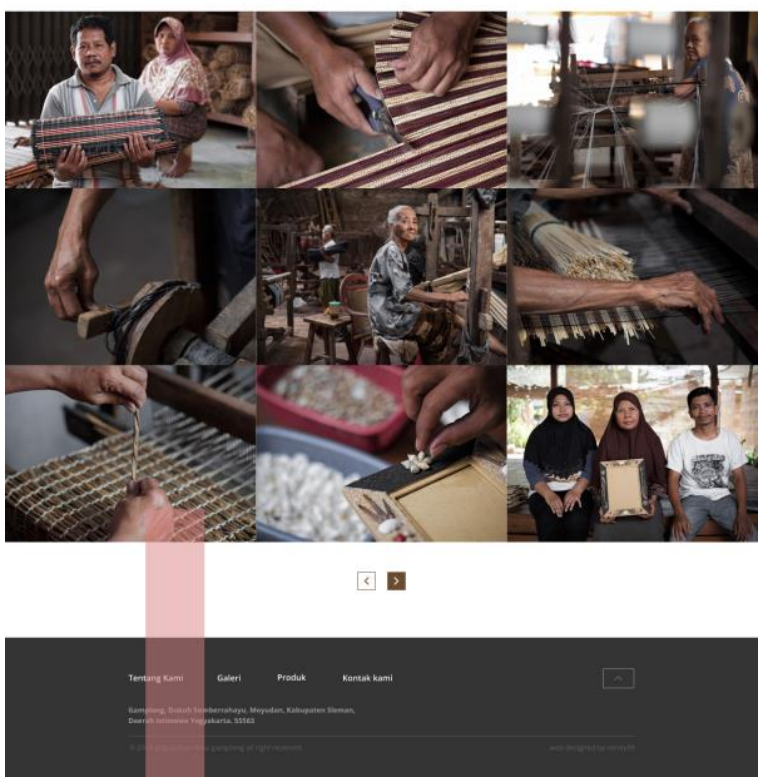

Gambar 5. Halaman galeri

(Sumber: Dokumentasi Penulis)
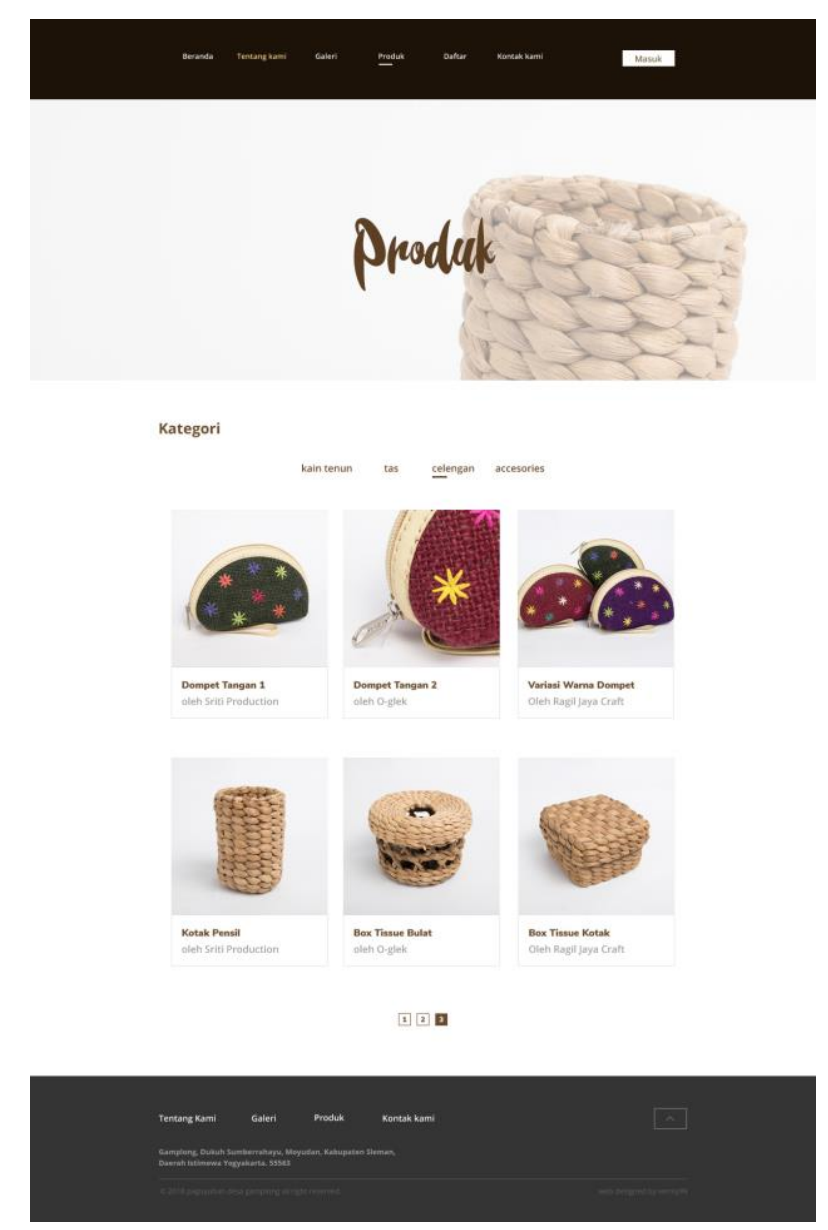

Gambar 6. Halaman produk (Sumber: Dokumentasi Penulis)

\subsection{Pembahasan}

Sebagai mana dilakukan oleh Firmansyah (2016), Ali dkk (2016) dan Caesaron (2015), cara mengevaluasi antarmuka web profile Desa Wisata Kerajinan Gamplong yang telah didesain menggunakan metode user experience ini menggunakan metode kualitatif evaluasi heuristik. Evaluasi heuristik dilakukan dengan menggunakan sepuluh aturan evaluasi heuristik Nielsen (1995) sebagai acuan dalam melakukan evaluasi usability pada desain user interface. Menurut Oracle (2012), metode evaluasi heuristik bisa digunakan selama inisialisasi, konfigurasi dan kustomisasi pengembangan sebuah aplikasi.

Hasil evaluasi heuristik berdasarkan Nielsen disajikan pada Tabel 1. Rekomendasi dari hasil evaluasi ini bisa dijadikan landasan untuk perbaikan tahap berikutnya.

\begin{tabular}{|r|l|l|}
\hline No. & \multicolumn{1}{|c|}{ Deskripsi } & \multicolumn{1}{|c|}{ Rekomendasi } \\
\hline 1. & Visibility of system status (feedback) & $\begin{array}{l}\text { Situs web sudah mengindikasikan } \\
\text { keberadaan pengguna dengan adanya judul } \\
\text { atau header di tiap halam web }\end{array}$ \\
\hline 2. & Match between system and the real & Penggunaan bahasa dan istilah jelas \\
\hline
\end{tabular}




\begin{tabular}{|r|l|l|}
\hline No. & \multicolumn{1}{|c|}{ Deskripsi } & \multicolumn{1}{|c|}{ Rekomendasi } \\
\hline 3. & world & User control and freedom \\
\hline 4. & Consistency and standards & $\begin{array}{l}\text { Perlu ditingkatkan adanya tombol navigasi } \\
\text { yang memiliki banyak fungsi, sehingga } \\
\text { pengguna bebas mengontrol pekerjaannya. }\end{array}$ \\
\hline 5. & Error prevention & $\begin{array}{l}\text { Terdapat kesesuaian judul dan header } \\
\text { dengan link tujuan. Konsisten dalam } \\
\text { penamaan dan tata bahasa pada menu. }\end{array}$ \\
\hline 6. & Recognition rather than recall & $\begin{array}{l}\text { Perlu diberikan aksi pencegahan } \\
\text { kesalahan. }\end{array}$ \\
\hline 7. & Flexibility and efficiency of use & $\begin{array}{l}\text { Sudah baik. } \\
\text { dwibahasa }\end{array}$ \\
\hline 8. & Aesthetic and minimalist desain & Sudah baik \\
\hline 9. & $\begin{array}{l}\text { Help } \text { users recognize, diagnose, and } \\
\text { recovers from errors }\end{array}$ & $\begin{array}{l}\text { Perlu adanya penjelasan kesalahan dan } \\
\text { solusi mengatasinya }\end{array}$ \\
\hline 10. & Help and documentation & $\begin{array}{l}\text { Perlu adanya menu help yang bisa diakses } \\
\text { kapan saja }\end{array}$ \\
\hline
\end{tabular}

Tabel 1: Rangkuman Hasil Evaluasi Heuristik

(Sumber: Dokumentasi Penulis)

\section{KESIMPULAN}

Penelitian ini berhasil menciptakan prototype web profile Desa Wisata Dan Kerajinan Gamplong Sleman dengan metode desain user experience sebagai sarana menyajikan informasi wisata, ruang pamer produk kerajinan tenun dan non tenun, kegiatan wisata yang dilaksanakan desa wisata dan kerajinan Gamplong. Hasil evaluasi heuristik atas antarmuka prototype web profile Desa Wisata Dan Kerajinan Gamplong Sleman sebagai acuan evaluasi usability, mengemukakan bahwa perlu penanganan yang lebih baik untuk aspek error prevention, flexibility and efficiency of use, help user recognize, diagnose, and recover from errors dan help and documentation. Penanganan tersebut mencakup fitur pencegahan kesalahan, penambahan menu help, dan fitur dwibahasa. Secara keseluruhan Aesthetic and minimalist desain, Consistency and standards, Match between system and the real world dan Visibility of system status (feedback) sudah baik.

\section{DAFTAR PUSTAKA}

$\underline{\text { Referensi dari buku: }}$

Garrett JJ. 2011. The Elements of User Experience: User-Centered Design for the Website and Beyond, Ed ke-2. Berkeley (US): New Riders.

Moule, Jodie. 2012. Killer UX Design: Create User Experiences to Wow Your Visitor $1^{\text {st }}$ Edition. Australia: Sitepoint Pty. Ltd. 
$\underline{\text { Referensi dari artikel jurnal: }}$

Ali, Amir., Pramana, Edwin., Tjandra, Suhatati. 2016. Evaluasi Heuristik Pada Web Based Learning Untuk Meningkatkan Aspek Usability Sistem. Jurnal Insand Comtech, vol. 1, no. 1 , pp. $17-25$.

Caesaron, Dino. 2015. Evaluasi Heuristic Desain Antar Muka (Interface) Portal Mahasiswa (Studi Kasus Portal Mahasiswa Universitas X). Jurnal Metris, pp. 9 - 14.

Supriyanta \& Nisa, Khoirun. 2015. Perancangan Website Desa Wisata Karangrejo Sebagai Media Informasi dan Promosi. Jurnal Bianglala Informatika, Vol. 3, No.2.

\section{$\underline{\text { Referensi dari conference paper: }}$}

Firmansyah, Ricky. 2016. Evaluasi Heuristik Pada Desain Interface Aplikasi My Indihome. Prosiding Seminar Nasional Ilmu Pengetahuan dan Teknologi Komputer Nusa Mandiri, pp. $66-73$.

Ichsan, Muhammad F; Sabariah, Mira K \& Effendy, Veronikha. 2015. Pemodelan User Experience Aplikasi Media Interaktif Pengenalan Menggambar untuk Pendidikan Anak Usia Dini Menggunakan Metode Hierarchical Task Analysis. e-Proceeding of Engineering, Vol.2, No.2, pp. 5969 - 5976.

Yeskasafitri, Annisa; Kusumo, Dana S \& Sabariah, Mira K. 2015. Perancangan Model User Interface untuk Website E-Commerce Liliput Edu Toys dengan Metode Paper Prototyping. e-Proceeding of Engineering, Vol.2, No.1, pp. 1529 - 1534.

$\underline{\text { Referensi dari disertasi: }}$

Asdarianto, Zulkifli. 2017. Perancangan User Experience Pebisnis Pada Sistem Pemasaran Waralaba Produk Umkm Menggunakan Metode Five Planes [skripsi]. Bogor: Institut Pertanian Bogor.

Keinanen, Liisa-Maija. 2011. Touch Screen Mobile Devices Invading the Internet: UX Guidelines Towards One Web [Thesis]. Greater Helsinki: Aalto University.

Orlova, Mariia. 2016. User Experience Design ( Ux Design ) In A Website Development Website Redesign [Bachelor's Thesis]. Mikkeli: Mikkeli University of Applied Sciences.

$\underline{\text { Referensi dari website: }}$

Nielsen, J. 1995. 101 Introduction to Usability. [Online]. URL: http://www.nngroup.com/articles/usability-101-introduction-to-usability/. Diakses: 15 Maret 2017.

Oracle. 2012. User Experience Direct (UX Direct) FAQ: How to conduct Heuristic Evaluation. [Online]. URL: http://laerer.rhs.dk/vibekes/sym 3 sem efterår 14/artikler, kapitler m.v/how-to-conduct-heuristic-evaluation.pdf. Diakses: 12 Oktober 2018. 